\title{
Calcitonin Levels in Thyroid Disease Are Not Affected by Autoimmune Thyroiditis or Differentiated Thyroid Carcinoma
}

\author{
Fabio Maino $^{a}$ Cristina Dalmiglio ${ }^{a}$ Nicoletta Benenati ${ }^{a} \quad$ Michele Campanile $^{a}$ \\ Tania Pilli ${ }^{a}$ Raffaella Forleo ${ }^{a}$ Lucia Brilli $^{a}$ Cristina Ciuoli ${ }^{a}$ Silvia Cantara ${ }^{a}$ \\ Marco Capezzone ${ }^{a}$ Alessandra Cartocci $^{\text {b }}$ Furio Pacini $^{c}$ \\ Maria Grazia Castagna ${ }^{a}$
}

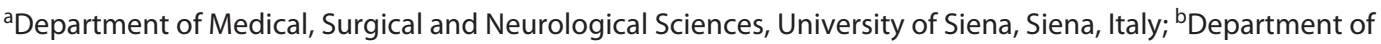
Medical Biotechnologies, University of Siena, Siena, Italy; 'Humanitas Clinical Institute, Humanitas University, Rozzano, Italy

\section{Keywords}

Autoimmune thyroiditis - Calcitonin - Medullary thyroid cancer · Differentiated thyroid cancer

\section{Abstract \\ Introduction: Association between hypercalcitoninemia and pathological conditions such as autoimmune thyroiditis (AIT) or differentiated thyroid carcinoma (DTC) has been ad- dressed, with conflicting results. We evaluated the preva- lence and the clinical relevance of elevated basal serum cal- citonin (CT) levels in non-neoplastic (nodular goiter [NG] and AIT) and neoplastic thyroid diseases (DTC). Methods: We ret- rospectively evaluated 3,250 consecutive patients with thy- roid nodular disease who underwent fine-needle aspiration cytology with adequate sample. After exclusion of medullary thyroid cancer (MTC) patients were divided according to the presence/absence of thyroid autoimmunity into NG or nod- ular autoimmune thyroiditis (N-AIT) and, according to cyto- logical results, in benign or suspicious/malignant nodules. Results: One hundred ninety-seven/3,250 patients $(6.0 \%)$ showed CT level $>10$ pg/mL. In 11/3,250 (0.3\%) cases, a final histological diagnosis of MTC was made, while the remain-}

ing 186/3,250 patients (5.7\%) had non-MTC-related hypercalcitoninemia (CT>10 pg/mL). According to cytological diagnosis, the rate of hypercalcitoninemia was similar in class II and class V-VI groups (5.4 vs. 6.9\%, $p=0.4$ ). The occurrence of hypercalcitoninemia was significantly higher in patients with NG $(166 / 2,634[6.3 \%])$ than in patients with N-AIT $(20 / 605[3.3 \%])(p=0.004)$. However, after matching by sex, no difference was found between the 2 groups (NG and NAIT). These results were confirmed in 598 patients submitted to surgery. Conclusions: AIT and DTC seem not to affect serum CT levels in patients with thyroid nodules. Therefore, hypercalcitoninemia, in these patients, should be submitted to the same diagnostic workup than patients without AIT or DTC.

(C) 2020 European Thyroid Association Published by S. Karger AG, Basel

\section{Introduction}

Calcitonin (CT), a 32-amino acid calcium-lowering peptide secreted by the C-cells (parafollicular cells) of the thyroid, is used as a marker for the diagnosis and the follow-up of medullary thyroid cancer (MTC) [1]. In pa-
Maria Grazia Castagna

Department of Medical Sciences, University of Siena, Policlinico Santa Maria alle Scotte Viale Bracci 16 
tients with a nodular thyroid, the measurement of basal serum CT levels has been proposed as a systematic screening method for MTC $[2,3]$. The routine measurement of CT in patients with thyroid nodules can be useful in the early diagnosis of MTC and C-cell hyperplasia $(\mathrm{CCH})$ and several studies suggested that a cutoff of 10 $\mathrm{pg} / \mathrm{mL}$ had a very high negative predictive value in spite of a low positive predictive value, with a high rate of false-positive results [4-10]. Basal CT levels $>100 \mathrm{pg} / \mathrm{mL}$ are widely considered an indication for surgery [1], while the management of patients showing a mild increase in basal serum CT levels appears to be more controversial [10]. Indeed, the elevation of basal serum CT levels has also been associated with clinical factors (i.e., sex, age, and cigarette smoking) [11-14], pathological conditions (i.e., small-cell lung carcinoma, chronic renal failure, hypergastrinemia, neuroendocrine tumors, autoimmune thyroiditis (AIT), and micropapillary thyroid carcinoma) $[15,16]$ and pharmacological agents (i.e., proton-pump inhibitor, glucocorticoids, and $\beta$-blockers) $[17,18]$. Consequently, while the reported prevalence of MTC among patients with thyroid nodules is low $(0.26-1.30 \%)$, the frequency of elevated basal CT levels reported in these patients is much higher (0.66.8\%) [4-10].

The association between AIT and hypercalcitoninemia is still controversial. Some authors have reported $\mathrm{CCH}$ in some thyroid specimens affected by Hashimoto's thyroiditis [19], while others have reported decreased basal serum CT levels that are probably caused by atrophy, fibrosis, and destruction of both follicular and C-cells [15]. Grani et al. [15] retrospectively evaluated the association between hypercalcitoninemia and the presence of anti-TPO antibodies in 1,073 patients with thyroid nodules. The prevalence of patients with a basal serum CT value $>10 \mathrm{pg} / \mathrm{mL}$, considered as "suspicious", was not significantly different between patients with thyroid autoimmunity and those without (3.9 vs. $3.0 \%)$.

Differentiated thyroid carcinoma (DTC) has been reported to be associated with $\mathrm{CCH}$ and high levels of basal CT [18]. It has been proposed that these tumors may release substances that have a paracrine stimulatory action on the C-cells and eventually lead to an increase of serum CT levels. In this regard, Verga et al. [20] analyzed the prevalence and the histological patterns of $\mathrm{CCH}$ in 15 patients with multinodular goiter and hypercalcitoninemia. They found that in $20 \%$ of them, the histological diagnosis of DTC was associated with $\mathrm{CCH}$. Therefore, they speculated the possible over expression in thyroid cancer of paracrine growth factors influencing the surrounding C-Cell. Nevertheless, currently the possible association between hypercalcitoninemia and DTC is still debated [16]. Therefore, the aim of our study was to evaluate the prevalence and the clinical relevance, especially in terms of utility in MTC detection, of elevated basal serum CT levels in non-neoplastic (nodular goiter (NG) and AIT) and neoplastic thyroid diseases (DTC).

\section{Materials and Methods}

\section{Study Population}

We retrospectively evaluated 3,250 (2,546 females and 704 males, mean age $57 \pm 14$ years, range 8-94 years) consecutive patients with thyroid nodular disease who underwent fine-needle aspiration cytology (FNAC) with adequate cytology from 2003 to 2019. Exclusion criteria were (1) patients with a family history of MTC or MEN syndrome; (2) patients with known presence of kidney failure, hyperparathyroidism, chronic atrophic gastritis, neuroendocrine tumor or lung cancer; (3) patients without serum CT measurement at the time of FNAC.

All patients were submitted to biochemical evaluation (TPOAb, TgAb, FT4, FT3, TSH, and CT) and neck ultrasonography (US). At the neck ultrasound, 2,580/3,250 (79.4\%) patients had multiple NG while $670 / 3,250$ (20.6\%) had a solitary nodule. The mean diameter of nodules was $25.3 \pm 13.4 \mathrm{~mm}$. According to Bethesda classification [21], FNAC was benign (class II) in 2,788/3,250 $(85.8 \%)$ patients, atypia of undetermined significance/follicular lesion of undetermined significance (AUS/FLUS)-follicular neoplasm/suspicious for follicular neoplasm (FN/SFN) (class III-IV) was found in 264/3,250 (8.2\%) patients, while suspicious for malignancy (class V) and malignant (class VI) cytologies were observed in 48/3,250 (1.5\%) patients and in 145/3,250 (4.5\%) patients, respectively. Cytological diagnosis of MTC was reported in $5 / 3,250(0.1 \%)$ patients.

Based on clinical, biochemical, and ultrasound data available at the time of FNAC, patients with thyroid nodules were classified into 2 groups: (1) nodular autoimmune thyroiditis (N-AIT) in the presence of positivity of anti-thyroid antibodies, defined by TgAb and/or TPOAb $\geq 100 \mathrm{UI} / \mathrm{L}$, with or without a "thyroiditis" pattern on neck US (diffusely hypoechoic echogenicity, parenchymal heterogeneity, and echogenic septation) and with or without hypothyroidism. Patients with a "thyroiditis" pattern on neck US but with a mild increase of TgAb and/or TPOAb $(<100 \mathrm{UI} / \mathrm{L})$ with or without hypothyroidism were also considered as affected by $\mathrm{N}$ AIT; (2) the diagnosis of NG was made in the presence of negative anti-thyroid antibodies, no "thyroiditis" pattern on US or in the presence of mild positive anti-thyroid antibodies (TgAb and/or TPOAb $<100$ UI/L) without "thyroiditis" pattern on US. Six hundred seven patients/3,250 (18.7\%) were classified in the N-AIT group and 2,643/3,250 (81.3\%) in the NG group.

\section{Methods}

Serum TSH was measured by chemiluminescent immunometric assay (Immulite 2000; DPC Diagnostic Products Corporation, Los Angeles, CA, USA). Measurement of TgAb and TPOAb was 
performed with a solid-phase, enzyme-labeled, chemiluminiscent sequential immunometric assay (Immulite 2000; Siemens Medical Solutions Diagnostics, Los Angeles, CA, USA). TgAb values $\leq 45$ $\mathrm{IU} / \mathrm{mL}$ and TPOAb $\leq 35 \mathrm{IU} / \mathrm{mL}$ were considered to be negative, while values $\geq 100$ for both antibodies were considered to be clearly positive ([2-fold the upper normal level, with a higher sensitivity for Hashimoto thyroiditis diagnosis] [22]). Histological thyroiditis was defined on the basis of the histological report, irrespective of diffuse or focal lymphocitic thyroiditis.

From 2003 to 2019, serum CT was measured in the same laboratory, by 2 -site immunoradiometric assay with analytic sensitivity of $1.5 \mathrm{pg} / \mathrm{mL}$ and functional sensitivity of $4 \mathrm{pg} / \mathrm{mL}$, without differences in CT range regarding sex (IRMA-hCT Cisbio Bioassays - Parc Marcel Boiteux, Codolet France). Patients with basal CT levels $>5$ and $>10 \mathrm{pg} / \mathrm{mL}$ were considered to have hypercalcitoninemia.

Neck US was performed by experienced endocrinologists (members of our staff) using a high resolution ultrasound color Doppler apparatus (AU 590 Asynchronous; Esaote Biomedica, Firenze, Italy) with a 7.5-MHz linear transducer. The anteroposterior (AP), transverse (T), and longitudinal (L) diameters of each nodule were measured by US. The volume of nodules was calculated using the ellipsoid formula $(\mathrm{AP} \times \mathrm{T} \times \mathrm{L} \times \pi / 6)\left(\mathrm{cm}^{3}\right)$. FNAC was performed under ultrasound guidance using a 23/25-gauge needle and only nodules clearly distinct from the surrounding parenchyma were submitted to FNAC. The material was air dried, stained with May-Grunwald Giemsa and interpreted by an experienced cytologist. Cytological results were reported according to the criteria of the 2017 Bethesda classification for reporting thyroid cytopathology [21]: benign (class II), AUS/FLUS-FN/SFN (class III-IV), suspicious for malignancy (class V), and malignant (class VI) nodules. Patients with multinodular goiter were given the cytological category with the highest risk (class II < class III-IV < class V-VI). A written informed consent was obtained from all study patients and the study was conducted in accordance with the principles set out in the Declaration of Helsinki.

\section{Statistical Analysis}

Epidemiological data are presented as the mean \pm SD and median when needed. The $t$ test for independent data or the MannWhitney test were performed for normally or non-normally distributed variables, respectively. To evaluate significant differences in data frequency we analyzed contingency tables. Tables with size larger than $2 \times 2$ were examined by the $\chi^{2}$ test or a numerical approximation of the Fisher's exact test, when all cell frequencies were $>4$ or not, respectively. To evaluate the impact of thyroid cancer on serum CT levels in the cytological series, patients with indeterminate cytology (class III-IV) were excluded from the analysis and patients with suspicious or malignant cytology (class V-VI) were grouped. Linear regression models were built to examine relationship between CT values and thyroid volume. We performed a multivariate analysis using a stepwise procedure based on the Akaike criterion to identify variables with independent prognostic significance for serum CT levels and to calculate the odds ratio. Statistical analysis was performed using the software StatView for Windows version 5.0.1 (SAS Institute, Cary, NC, USA) and the SPSS Statistics version 22.0. A $p$ value $<0.05$ was considered statistically significant.

Hypercalcitoninemia in Non-MTC

Thyroid Nodules

\section{Results}

\section{Hypercalcitoninemia and Medullary Thyroid}

\section{Carcinoma}

One hundred ninety-seven/3,250 patients (6.0\%) showed a basal CT level $>10 \mathrm{pg} / \mathrm{mL}$. Among patients with hypercalcitoninemia, 54/197 (27.4\%) were submitted to surgery. In 11/54 (20.3\%), a histological diagnosis of MTC was made. In the remaining 186 patients, the diagnosis of MTC was excluded on the basis of histological results ( $n=43 / 186,23.1 \%)$ or additional test $(n=143 / 186$, $76.9 \%)$ such as stimulating test (calcium gluconate administration or pentagastrin test) and/or CT measurement in fine-needle aspirate washout fluid of the suspicious nodules. In the subgroup of patients with hypercalcitoninemia without MTC $(n=43)$, the main indication for surgery was a large goiter in 19/43 (44.2\%), suspicious/malignant cytology in 12/43 (27.9\%), class III-IV cytology in $8 / 43(18.6 \%)$, and CT levels suspicious for MTC in 4/43 (9.3\%). Basal serum CT levels in MTC patients were $915.3 \pm 701.0 \mathrm{pg} / \mathrm{mL}$ (range $12-1,992 \mathrm{pg} / \mathrm{mL}$, median $923 \mathrm{pg} / \mathrm{mL}$ ) significantly higher than that observed in patients without MTC (mean $14.6 \pm 7.3 \mathrm{pg} / \mathrm{mL}$ [range 10.1-57.9 pg/mL, median $11.8 \mathrm{pg} / \mathrm{mL}$ ] $)(p<$ 0.0001).

\section{Hypercalcitoninemia without Medullary Thyroid Carcinoma}

Patients with MTC were excluded from the statistical analysis and the final study group included 3,239 patients (Table 1). The mean value of serum CT and the rate of patients with hypercalcitoninemia (defined as serum CT levels $>5$ or $>10 \mathrm{pg} / \mathrm{mL}$ ) were significantly higher in males than females $(p<0.0001)$. In $186 / 3,239$ (5.7\%) patients with basal serum CT levels $>10 \mathrm{pg} / \mathrm{mL}$, the mean CT value was $14.6 \pm 7.3 \mathrm{pg} / \mathrm{mL}$ (range $10.1-57.9 \mathrm{pg} / \mathrm{mL}$, median $11.8 \mathrm{pg} / \mathrm{mL}$ ) and CT levels were significantly higher in men (mean $16.1 \pm 9.3$, range $10.1-57.9 \mathrm{pg} / \mathrm{mL}$, median value $12.2 \mathrm{pg} / \mathrm{mL}$ ) than in females (mean $13.1 \pm 4.0$, range $10.1-31.6 \mathrm{pg} / \mathrm{mL}$, median value $11.7 \mathrm{pg} / \mathrm{mL})(p<0.0001)$. The thyroid volume was significantly larger in males than females (median volume $31 \mathrm{~mL}$ in men vs. $20 \mathrm{~mL}$ in females, $p<0.0001$ ). A significant correlation between basal CT value and thyroid volume was observed $(p<0.0001)$.

\section{Hypercalcitoninemia and Differentiated Thyroid Cancer (DTC) \\ Cytological Results}

To evaluate the association between serum CT values and thyroid nodule cytology, we classified our patients ac- 
Table 1. Epidemiological, clinical, and biochemical features of the cohorts (MTC excluded)

\begin{tabular}{|c|c|c|c|c|}
\hline & Total group & Male & Female & $\begin{array}{l}p \text { value } \\
(\mathrm{M} \text { vs. F) }\end{array}$ \\
\hline$N(\%)$ & 3,239 & $700(21.6 \%)$ & $2,539(78.4 \%)$ & \\
\hline Age $(y r)$ & & & & $p<0.0001^{\mathrm{a}}$ \\
\hline Median & 59 & 61 & 58 & \\
\hline Mean \pm SD & $57.1 \pm 14$ & $59.5 \pm 13.3$ & $56.5 \pm 14$ & \\
\hline Range & $8-94$ & $16-89$ & $8-94$ & \\
\hline Hyper-CT (cutoff 5 pg/mL), ${ }^{\mathrm{b}} n(\%)$ & $769(23.7)$ & $300(42.8)$ & $469(18.4)$ & $p<0.0001^{\mathrm{c}}$ \\
\hline Hyper-CT value $(>5 \mathrm{pg} / \mathrm{mL})$ & & & & $p<0.0001^{\mathrm{d}}$ \\
\hline Median & 7.9 & 8.4 & 7.6 & \\
\hline Mean \pm SD & $8.9 \pm 5.0$ & $10.0 \pm 6.7$ & $8.2 \pm 3.2$ & \\
\hline Range & $5.0-57.9$ & $5.0-57.9$ & $5.0-31.6$ & \\
\hline Hyper-CT (cutoff 10 pg/mL), $n(\%)$ & $186(5.7)$ & $95(13.5)$ & $91(3.6)$ & $p<0.0001^{\mathrm{c}}$ \\
\hline Hyper-CT value $(>10 \mathrm{pg} / \mathrm{mL})$ & & & & $p<0.0001^{\mathrm{d}}$ \\
\hline Median & 11.8 & 12.2 & 11.7 & \\
\hline Mean \pm SD & $14.6 \pm 7.3$ & $16.1 \pm 9.3$ & $13.1 \pm 4$ & \\
\hline Range & $10.1-57.9$ & $10.1-57.9$ & $10.1-31.6$ & \\
\hline Thyroid gland volume, $\mathrm{mL}$ & & & & $p<0.0001^{\mathrm{d}}$ \\
\hline Median & 25 & 31 & 20 & \\
\hline Mean \pm SD & $35.1 \pm 30.4$ & $42.6 \pm 34.9$ & $27.1 \pm 22.2$ & \\
\hline Range & $6-240$ & $9-240$ & 6-127 & \\
\hline
\end{tabular}

cording to the 2017 Bethesda classification for reporting thyroid cytopathology [21]. To investigate the correlation between serum CT levels and the cytological diagnosis of thyroid cancer, patients were classified into 2 groups: benign (Class II: $n=2,786)$ and suspicious/malignant cytology (Class V-VI, $n=189$ ). Patients with Class III-IV cytology $(n=264)$ were excluded from the analysis.

The prevalence of hypercalcitoninemia defined according to the cutoff of $10 \mathrm{pg} / \mathrm{mL}$, was similar in class II and class V-VI groups $(150 / 2,786,5.4 \%$ vs. $13 / 189,6.9 \%, p=0.4)$, even when males $(76 / 578,13.1 \%$ vs. $8 / 53,15 \%, p=0.6)$ and female $(74 / 2,208,3.3 \%$ vs. $5 / 136,3.6 \%, p=0.8)$ were analyzed separately (Table 2). Similarly, no differences in the rate of hypercalcitoninemia were also observed when a lower cutoff $(5 \mathrm{pg} / \mathrm{mL})$ of calcitonin was used (Table 2). Moreover, serum CT levels were not different between patients with class II and class III-IV cytology, both in the total group than in males and females (Table 2).

Histological Results

The potential correlation between serum CT values and DTC was also evaluated in a subgroup of patients submitted to thyroidectomy ( $n=598 / 3,239,18.5 \%)$ (Table 3). Benign histology was reported in $353 / 598$ patients $(59.0 \%)$. In
240/598 patients (40.3\%), a histological diagnosis of DTC was made. Papillary thyroid cancer was diagnosed in 228/241 (94.6\%) and follicular thyroid cancer in 13/241 (5.4\%) patients. At last, in 4/598 (0.7\%) patients, a diagnosis of $\mathrm{CCH}$ was made. All patients with a histological diagnosis of $\mathrm{CCH}$ had hypercalcitoninemia, while no differences in the rate of hypercalcitoninemia, defined according to the cutoff of $10 \mathrm{pg} / \mathrm{mL}$, was observed between benign histology $(19 / 353,5.4 \%)$ and DTC $(21 / 241,8.7 \%, p=0.13)$. Similarly, no differences in the prevalence of hypercalcitoninemia and in the serum CT levels were found when the same analysis was performed according to sex (Table 3). Using a lower serum CT cutoff $(5 \mathrm{pg} / \mathrm{mL})$, no differences in the rate of hypercalcitoninemia was observed between benign and malignant nodules both in the total group $(p=0.55)$, in males (0.86) and females $(p=0.31)$ subgroups (Table 3 ). Moreover, serum CT levels were not different between patients with benign nodules and DTC, in the total group, in males and females (Table 3).

\section{Hypercalcitoninemia and AIT}

Clinical and Biochemical Diagnosis

As reported in Table 4, 2,634/3,239 (81.3\%) patients were classified as having NG and 605/3,239 (18.7\%) pa- 
Table 2. Hypercalcitoninemia prevalence and basal serum CT levels according to cytological diagnosis (class IIIIV excluded, $n=264$ )

\begin{tabular}{|c|c|c|c|}
\hline & \multicolumn{2}{|c|}{ Bethesda classification } & \multirow[t]{2}{*}{$p$ value } \\
\hline & class II & class $\mathrm{V}-\mathrm{VI}$ & \\
\hline Total group, $n(\%), n=2,985$ & $2,786(93.6)$ & $189(6.4)$ & \\
\hline Hyper-CT (cutoff $5 \mathrm{pg} / \mathrm{mL}$ ), ${ }^{\mathrm{a}} n(\%)$ & $641(22.9)$ & $46(24.3)$ & $0.79^{\mathrm{b}}$ \\
\hline Hyper-CT value $(>5 \mathrm{pg} / \mathrm{mL})$ & & & $0.63^{c}$ \\
\hline Median & 7.9 & 7.8 & \\
\hline Mean \pm SD & $8.9 \pm 4.9$ & $9.5 \pm 7.3$ & \\
\hline Range & $5.0-57.9$ & $5.1-53.4$ & \\
\hline HyperCT (cutoff 10 pg/mL), $n(\%)$ & $150(5.4)$ & $13(6.9)$ & $0.4^{\mathrm{b}}$ \\
\hline Hyper-CT value $(>10 \mathrm{pg} / \mathrm{mL})$ & & & $0.6^{\mathrm{c}}$ \\
\hline Median & 11.9 & 11.8 & \\
\hline Mean \pm SD & $14.8 \pm 7.3$ & $15.8 \pm 11.7$ & \\
\hline Range & $10.1-57.9$ & $10.2-53.4$ & \\
\hline Female, $n(\%)$ & $2,208(94.2)$ & $136(5.8)$ & \\
\hline Hyper-CT (cutoff 5 pg/mL), ${ }^{a} n(\%)$ & $641(18.3)$ & $25(18.3$ & $1.0^{\mathrm{b}}$ \\
\hline $\mathrm{CT}$ value, $\mathrm{pg} / \mathrm{mL}$ & & & $0.47^{\mathrm{c}}$ \\
\hline Median & 7.6 & 7.7 & \\
\hline Mean \pm SD & $8.1 \pm 3.2$ & $8.4 \pm 3.2$ & \\
\hline Range & $5.0-31.6$ & $5.1-21$ & \\
\hline Hyper-CT (cutoff 10 pg/mL), $n(\%)$ & $74(3.3)$ & $5(3.6)$ & $0.8^{\mathrm{b}}$ \\
\hline Hyper-CT value $(>10 \mathrm{pg} / \mathrm{mL})$ & & & $0.9^{c}$ \\
\hline Median & 11.8 & 11.6 & \\
\hline Mean \pm SD & $13.1 \pm 4.0$ & $13.1 \pm 4.4$ & \\
\hline Range & $10.1-31.6$ & $10.3-21.0$ & \\
\hline Male, $n(\%)$ & $578(91.6)$ & $53(8.4)$ & \\
\hline Hyper-CT (cutoff 5 pg/mL), ${ }^{a} n(\%)$ & $247(42.7)$ & $21(39.6)$ & $0.77^{\mathrm{b}}$ \\
\hline $\mathrm{CT}$ value, $\mathrm{pg} / \mathrm{mL}$ & & & $0.83^{c}$ \\
\hline Median & 8.5 & 7.9 & \\
\hline Mean \pm SD & $10.1 \pm 6.7$ & $10.8 \pm 10.2$ & \\
\hline Range & $5.0-57.9$ & $5.2-53.4$ & \\
\hline Hyper-CT (cutoff $10 \mathrm{pg} / \mathrm{mL}$ ), $n(\%)$ & $76(13.1)$ & $8(15)$ & $0.6^{\mathrm{b}}$ \\
\hline Hyper-CT value $(>10 \mathrm{pg} / \mathrm{mL})$ & & & $0.7^{\mathrm{c}}$ \\
\hline Median & 12.2 & 12.0 & \\
\hline Mean \pm SD & $16.5 \pm 9.1$ & $17.5 \pm 14.7$ & \\
\hline Range & $10.1-57.0$ & $10.2-53.0$ & \\
\hline
\end{tabular}

Hyper-CT, hypercalcitoninemia; CT, calcitonin. ${ }^{a}$ According to functional sensitivity of our assay. ${ }^{b} \chi^{2}$ test. ${ }^{c}$ Mann-Whitney test.

tients as having N-AIT. The prevalence of hypercalcitoninemia defined according to the cutoff of $10 \mathrm{pg} / \mathrm{mL}$ was significantly higher in patients with NG $(166 / 2,634$ [6.3\%]) than patients with N-AIT $(20 / 605[3.3 \%])(p=$ $0.004)$. When the analysis was performed according to gender, no difference between NG and N-AIT was found both in males $(p=0.76)$ and females $(p=0.08)$. Similarly, no differences in the rate of hypercalcitoninemia were also observed when a lower cutoff $(5 \mathrm{pg} / \mathrm{mL})$ of calcitonin was used (Table 4). Moreover, the serum CT levels were not different between patients with NG and N-AIT both in the total group than in males and females (Table 4).
The same analysis was performed according to the presence or absence of TPOAb using a cutoff of $>100 \mathrm{IU} /$ $\mathrm{mL}$. TPOAb were clearly positive $(\geq 100 \mathrm{IU} / \mathrm{mL}$, TPOAb+ group) in $440 / 3,239$ (13.6\%) patients and mild positive $(<100 \mathrm{IU} / \mathrm{mL})$ or negative $(<45 \mathrm{IU} / \mathrm{mL})$ in $2,799 / 3,239$ (86.4\%) patients (TPOAb- group). The prevalence of hypercalcitoninemia defined according to the cutoff of 10 $\mathrm{pg} / \mathrm{mL}$ did not differ between the 2 groups of patients (18/440 [4.1\%] in TPOAb+ group vs. $168 / 2,799$ [6.0\%] in TPOAb- group, $p=0.1)$. Similar results were observed also when considering only males (7/44 [15.9\%] in $\mathrm{TPOAb}+$ group vs. 88/656 [13.4\%] in TPOAb- group, 
Table 3. Hypercalcitoninemia prevalence and basal serum CT levels according to histological diagnosis in $598 / 3,239$ patients submitted to thyroidectomy (CCH patients were excluded, $n=4$ )

\begin{tabular}{|c|c|c|c|}
\hline & \multicolumn{2}{|c|}{ Histological results } & \multirow[t]{2}{*}{$p$ value } \\
\hline & benign & DTC & \\
\hline Total group, $n(\%), n=594$ & $353(59.4)$ & $241(40.5)$ & \\
\hline Hyper-CT (cutoff $5 \mathrm{pg} / \mathrm{mL}$ ), ${ }^{\mathrm{a}} n(\%)$ & $81(22.9)$ & $61(25.3)$ & $0.55^{\mathrm{b}}$ \\
\hline Hyper-CT value $(>5 \mathrm{pg} / \mathrm{mL})$ & & & $0.18^{\mathrm{c}}$ \\
\hline Median & 8.0 & 8.3 & \\
\hline Mean \pm SD & $9.1 \pm 6.3$ & $10.9 \pm 9.7$ & \\
\hline Range & $5.1-57.9$ & $5.1-64.5$ & \\
\hline Hyper-CT (cutoff $10 \mathrm{pg} / \mathrm{mL}$ ), $n(\%)$ & $19(5.4)$ & $21(8.7)$ & $0.13^{\mathrm{b}}$ \\
\hline Hyper-CT value $(>10 \mathrm{pg} / \mathrm{mL})$ & & & $0.86^{\mathrm{c}}$ \\
\hline Median & 12.4 & 12.2 & \\
\hline Mean \pm SD & $15.6 \pm 10.6$ & $18.0 \pm 14.2$ & \\
\hline Range & $10.2-57.9$ & $10.1-64.5$ & \\
\hline Female, $n(\%)$ & $260(59.6)$ & $176(40.4)$ & \\
\hline Hyper-CT (cutoff $5 \mathrm{pg} / \mathrm{mL}$ ), ${ }^{\mathrm{a}} n(\%)$ & $43(16.5)$ & $36(20.4)$ & $0.31^{\mathrm{b}}$ \\
\hline Hyper-CT value $(>5 \mathrm{pg} / \mathrm{mL})$ & & & $0.18^{c}$ \\
\hline Median & 7.6 & 8.3 & \\
\hline Mean \pm SD & $8.4 \pm 3.4$ & $10.6 \pm 9.9$ & \\
\hline Range & $5.1-19.7$ & $5.1-64.5$ & \\
\hline Hyper-CT (cutoff $10 \mathrm{pg} / \mathrm{mL}), n(\%)$ & $10(3.8)$ & $10(5.6)$ & $0.48^{\mathrm{b}}$ \\
\hline Hyper-CT value $(>10 \mathrm{pg} / \mathrm{mL})$ & & & $0.93^{c}$ \\
\hline Median & 12.3 & 11.8 & \\
\hline Mean \pm SD & $13.7 \pm 3.0$ & $19.0 \pm 16.5$ & \\
\hline Range & $11-19.7$ & $10.1-64$ & \\
\hline Male, $n(\%)$ & $93(58.8)$ & $65(41.1)$ & \\
\hline Hyper-CT (cutoff $5 \mathrm{pg} / \mathrm{mL}$ ), ${ }^{\mathrm{a}} n(\%)$ & $38(40.9)$ & $25(38.5)$ & $0.86^{\mathrm{b}}$ \\
\hline Hyper-CT value $(>5 \mathrm{pg} / \mathrm{mL})$ & & & $0.51^{\mathrm{c}}$ \\
\hline Median & 8.2 & 7.9 & \\
\hline Mean \pm SD & $9.8 \pm 8.5$ & $11.2 \pm 9.7$ & \\
\hline Range & $5.1-57.9$ & $5.2-53.4$ & \\
\hline Hyper-CT (cutoff 10 pg/mL), $n(\%)$ & $9(9.6)$ & $11(16.9)$ & $0.22^{\mathrm{b}}$ \\
\hline Hyper-CT value $(>10 \mathrm{pg} / \mathrm{mL})$ & & & $0.79^{\mathrm{c}}$ \\
\hline Median & 12.4 & 12.4 & \\
\hline Mean \pm SD & $17.8 \pm 15.2$ & $17.1 \pm 12.4$ & \\
\hline Range & $10.2-57.9$ & $10.2-53.4$ & \\
\hline
\end{tabular}

$\mathrm{CCH}, \mathrm{C}$-cell hyperplasia; Hyper-CT, hypercalcitoninemia; DTC, differentiated thyroid carcinoma; CT, calcitonin. ${ }^{a}$ According to functional sensitivity of our assay. ${ }^{b} \chi^{2}$ test. ${ }^{c}$ Mann-Whitney test.

$p=0.6)$ and in females $(11 / 396[2.8 \%]$ in TPOAb+ group vs. $80 / 2,143$ [3.7\%] in TPOAb- group, $p=0.3$ ). No differences in the rate of hypercalcitoninemia were also observed when a lower cutoff $(5 \mathrm{pg} / \mathrm{mL})$ was used. Moreover, serum CT levels were not different between TPOAb+ and TPOAb-group, both in the total group than in males and females (Table 4).

\section{Histological Results}

The potential correlation between CT and AIT was also evaluated in a subgroup of patients with non-MTC hypercalcitoninemia submitted to thyroidectomy ( $n=$ $598 / 3,239,18.5 \%)$. Thyroiditis was found at histology in $127 / 598(21.2 \%)$ patients. The prevalence of hypercalcitoninemia, defined according to the cutoff of $10 \mathrm{pg} / \mathrm{mL}$, did not differ between patients with (7/127 [5.5\%]) and without histological thyroiditis $(37 / 471[7.8 \%])(p=0.44)$. As well, hypercalcitoninemia was not related to the presence of histological thyroiditis also when the analysis was performed according to sex $(p=0.07$ and $p=0.4$ in males and females, respectively). No differences in the rate of hypercalcitoninemia were also observed when a lower 
Table 4. Hypercalcitoninemia prevalence and basal serum CT levels according to clinical diagnosis

\begin{tabular}{|c|c|c|c|}
\hline & \multicolumn{2}{|c|}{ Clinical diagnosis } & \multirow[t]{2}{*}{$p$ value } \\
\hline & NG & N-AIT & \\
\hline Total group, $n(\%), n=3,239$ & $2,634(81.3)$ & $605(18.7)$ & \\
\hline Hyper-CT (cutoff $5 \mathrm{pg} / \mathrm{mL}$ ), ${ }^{\mathrm{a}} n(\%)$ & $646(24.5)$ & $123(20.3)$ & $0.02^{\mathrm{b}}$ \\
\hline Hyper-CT value $(>5 \mathrm{pg} / \mathrm{mL})$ & & & $0.06^{\mathrm{c}}$ \\
\hline Median & 8.1 & 7.6 & \\
\hline Mean \pm SD & $9.0 \pm 5.2$ & $8.2 \pm 3.5$ & \\
\hline Range & $5.0-57.9$ & $5.0-24.3$ & \\
\hline Hyper-CT (cutoff 10 pg/mL), $n(\%)$ & $166(6.3)$ & $20(3.3)$ & $0.004^{\mathrm{b}}$ \\
\hline Hyper-CT value $(>10 \mathrm{pg} / \mathrm{mL})$ & & & $0.66^{\mathrm{c}}$ \\
\hline Median & 11.8 & 11.6 & \\
\hline Mean \pm SD & $14.7 \pm 7.5$ & $14.0 \pm 5.0$ & \\
\hline Range & $10.1-57.9$ & $10.2-24.3$ & \\
\hline Female, $n(\%)$ & $1,991(78.4)$ & $548(21.6)$ & \\
\hline Hyper-CT (cutoff 5 pg/mL), ${ }^{a} n(\%)$ & $368(18.4)$ & $101(18.4)$ & $1.0^{\mathrm{b}}$ \\
\hline Hyper-CT value $(>5 \mathrm{pg} / \mathrm{mL})$ & & & $0.2^{\mathrm{c}}$ \\
\hline Median & 7.7 & 7.3 & \\
\hline Mean \pm SD & $8.3 \pm 3.3$ & $7.9 \pm 3.1$ & \\
\hline Range & $5.0-31.6$ & $5.1-23.5$ & \\
\hline Hyper-CT (cutoff 10 pg/mL), $n(\%)$ & $78(3.9)$ & $13(2.4)$ & $0.08^{\mathrm{b}}$ \\
\hline Hyper-CT value $(>10 \mathrm{pg} / \mathrm{mL})$ & & & $0.45^{\mathrm{c}}$ \\
\hline Median & 11.6 & 12.6 & \\
\hline Mean \pm SD & $13.0 \pm 3.9$ & $13.9 \pm 4.5$ & \\
\hline Range & $10.1-31.9$ & $10.3-23.5$ & \\
\hline Male, $n(\%)$ & $643(91.9)$ & $57(8.1)$ & \\
\hline Hyper-CT (cutoff $5 \mathrm{pg} / \mathrm{mL}$ ), ${ }^{\mathrm{a}} n(\%)$ & $278(43.2)$ & $22(38.6)$ & $0.57^{\mathrm{b}}$ \\
\hline Hyper-CT value $(>5 \mathrm{pg} / \mathrm{mL})$ & & & $0.89^{c}$ \\
\hline Median & 8.4 & 8.2 & \\
\hline Mean \pm SD & $10.1 \pm 6.9$ & $9.5 \pm 4.8$ & \\
\hline Range & $5.0-57.9$ & $5.0-24.3$ & \\
\hline Hyper-CT (cutoff 10 pg/mL), $n(\%)$ & $88(13.7)$ & $7(12.3)$ & $0.76^{\mathrm{b}}$ \\
\hline Hyper-CT value $(>10 \mathrm{pg} / \mathrm{mL})$ & & & $0.55^{\mathrm{c}}$ \\
\hline Median & 12.2 & 10.8 & \\
\hline Mean \pm SD & $16.3 \pm 9.4$ & $14.1 \pm 6.2$ & \\
\hline Range & $10.1-57.9$ & $10.2-24.3$ & \\
\hline
\end{tabular}

N-AIT, nodular autoimmune thyroiditis; NG, nodular goiter; Hyper-CT, hypercalcitoninemia, CT, calcitonin. ${ }^{a}$ According to functional sensitivity of our assay. ${ }^{b} \chi^{2}$ test. ${ }^{\mathrm{c}}$ Mann-Whitney test.

cutoff $(5 \mathrm{pg} / \mathrm{mL}$ ) was used (Table 5). Moreover, serum CT levels were not different between patients with (7/127 [5.5\%]) and without histological thyroiditis, both in the total group than in males and females groups (Table 5).

Follow-Up Data in Patients with Hypercalcitoninemia not Submitted to Surgery at the Time of the First

Evaluation

Among 143 patients with non-MTC-related hypercalcitoninemia and not submitted to surgery, long-term follow-up data (median follow-up of 9.9 years) were available only in $59 / 143(41.0 \%)$ patients. Four out of 59 (6.7\%) patients were submitted to surgery during follow-up: in 1 patient submitted to surgery because of a positive pentagastrin test, a $\mathrm{CCH}$ was found at histology, while in another patient, MTC $<1 \mathrm{~cm}$ (micro-MTC) was found. In this patient, surgery was performed for the presence of large cytologically benign nodule and previous external beam radiotherapy for laryngeal cancer. Therefore, we were not able to establish the real prevalence of MTC in this group because surgery was not performed in all patients.

Repeated measurement of basal CT during follow-up was available in 27/59 (45.7\%) patients. Serum CT be- 
Table 5. Hypercalcitoninemia prevalence and basal serum CT levels, according to histological presence/absence of AIT in 598/3,239 patients submitted to total thyroidectomy

\begin{tabular}{|c|c|c|c|}
\hline & \multicolumn{2}{|c|}{ Histological diagnosis } & \multirow[t]{2}{*}{$p$ value } \\
\hline & AIT & No-AIT & \\
\hline Total group, $n(\%), n=598$ & $127(21.2)$ & $471(78.8)$ & \\
\hline Hyper-CT (cutoff 5 pg/mL), ${ }^{\mathrm{a}} n(\%)$ & $26(20.4)$ & $120(25.4)$ & $0.29^{\mathrm{b}}$ \\
\hline Hyper-CT value $(>5 \mathrm{pg} / \mathrm{mL})$ & & & $0.65^{\mathrm{c}}$ \\
\hline Median & 7.9 & 8.3 & \\
\hline Mean \pm SD & $9.1 \pm 4.2$ & $10.5 \pm 9.0$ & \\
\hline Range & $5.1-23.5$ & $5.1-64.5$ & \\
\hline Hyper-CT (cutoff $10 \mathrm{pg} / \mathrm{mL}$ ), $n(\%)$ & $7(5.5)$ & $37(7.8)$ & $0.44^{\mathrm{b}}$ \\
\hline Hyper-CT value (>10 pg/mL) & & & $0.90^{\mathrm{c}}$ \\
\hline Median & 12.6 & 12.4 & \\
\hline Mean \pm SD & $14.7 \pm 4.7$ & $18.3 \pm 13.2$ & \\
\hline Range & $10.3-23.5$ & $10.4-64.5$ & \\
\hline Female, $n(\%)$ & $108(24.7)$ & $329(75.3)$ & \\
\hline Hyper-CT (cutoff 5 pg/mL), ${ }^{a} n(\%)$ & $20(18.5)$ & $60(18.2)$ & $1.0^{\mathrm{b}}$ \\
\hline Hyper-CT value (>5 pg/mL) & & & $0.73^{\mathrm{c}}$ \\
\hline Median & 7.8 & 8.1 & \\
\hline Mean \pm SD & $9.5 \pm 4.7$ & $9.6 \pm 8.0$ & \\
\hline Range & $5.1-23.5$ & $5.1-64.5$ & \\
\hline Hyper-CT (cutoff 10 pg/mL), $n$ (\%) & $7(6.4)$ & $14(4.2)$ & $0.4^{\mathrm{b}}$ \\
\hline Hyper-CT value $(>10 \mathrm{pg} / \mathrm{mL})$ & & & $0.94^{\mathrm{c}}$ \\
\hline Median & 12.6 & 11.9 & \\
\hline Mean \pm SD & $14.7 \pm 4.7$ & $17.8 \pm 14.0$ & \\
\hline Range & $10.3-23.5$ & $10.1-64.5$ & \\
\hline Male, $n(\%)$ & $19(11.8)$ & $142(88.2)$ & \\
\hline Hyper-CT (cutoff 5 pg/mL), ${ }^{a} n(\%)$ & $6(31.6)$ & $60(42.2)$ & $0.46^{\mathrm{b}}$ \\
\hline Hyper-CT value $(>5 \mathrm{pg} / \mathrm{mL})$ & & & $0.32^{\mathrm{c}}$ \\
\hline Median & 7.9 & 8.8 & \\
\hline Mean \pm SD & $7.6 \pm 1.4$ & $11.1 \pm 9.8$ & \\
\hline Range & $5.2-9.3$ & $5.1-57.9$ & \\
\hline Hyper-CT (cutoff $10 \mathrm{pg} / \mathrm{mL}$ ), $n(\%)$ & $0(0)$ & $23(16.2)$ & $0.07^{\mathrm{b}}$ \\
\hline Hyper-CT value $(>10 \mathrm{pg} / \mathrm{mL})$ & & & NA \\
\hline Median & NA & 12.7 & \\
\hline Mean \pm SD & NA & $18.6 \pm 13.0$ & \\
\hline Range & NA & $10.2-57.9$ & \\
\hline
\end{tabular}

AIT, autoimmune thyroiditis; Hyper-CT, hypercalcitoninemia; $\mathrm{CT}$, calcitonin; NA, not applicable. ${ }^{a}$ According to functional sensitivity of our assay. ${ }^{\mathrm{b}} \chi^{2}$ test. ${ }^{\mathrm{c}}$ Mann-Whitney test.

came undetectable $(<10 \mathrm{pg} / \mathrm{mL})$ in $17 / 27(63 \%)$ patients and remained stable in the remaining 10 cases. We observed significant lower serum CT values in the subgroup of patients in whom serum CT became undetectable (median $11 \mathrm{pg} / \mathrm{mL}$, range $10.4-41 \mathrm{pg} / \mathrm{mL}$ ) rather than those in which serum CT values remained stable or increased during the follow-up (median $24.7 \mathrm{pg} / \mathrm{mL}$, range 10.942). In $41 / 57$ (72\%) patients, routine neck ultrasound examination was performed and only in 6/41 (14.6\%) patients, a small increase of thyroid nodule size was observed.

\section{Risk Factors Associated with Hypercalcitoninemia}

We investigated, by multivariate analysis, several clinical parameters (sex, age, presence/absence of AIT, cytological and histological results, and thyroid volume) as possible risk factors for hypercalcitoninemia. To perform this analysis, we used serum CT as a continuous variable and also as a categorical variable (detectable or undetectable according to the 2 cutoffs used in the study). The only variable associated with serum CT levels was male sex. In particular, CT values in male patients were $2.824 \mathrm{pg} / \mathrm{mL}$ greater than females $(p=$ 
0.000 ), and male sex was associated with an odds ratio of 4.595 for hypercalcitoninemia (95\% CI 3.313-6.383, $p=0.000)$.

\section{Discussion}

The routinely measurement of CT in patients with thyroid nodules can be useful in the early diagnosis of MTC and $\mathrm{CCH}$ [2-9] and CT levels $>100 \mathrm{pg} / \mathrm{mL}$ are widely considered an indication for surgery [10]. On the contrary, the clinical significance of a mild increase of serum CT levels in patients with thyroid nodules appear to be more controversial. In the literature, the reported prevalence of hypercalcitoninemia not associated with MTC, range from 0.6 to $6.8 \%$ [10]. In our series, the overall prevalence of MTC was $0.3 \%$, while the occurrence of nonMTC-related hypercalcitoninemia was $5.7 \%$.

Several clinical and pathological factors may induce an increase of serum CT levels in patients with nodular disease without MTC. Among thyroid diseases, both DTC and AIT have been reported to be associated with hypercalcitoninemia but without conclusive results $[15,16,18$, 19]. To date, the potential correlation between the presence of hypercalcitoninemia and DTC has been poorly explored. To our knowledge, this association has been investigated in only 1 study including 494 patients with thyroid nodules, submitted to surgery: the prevalence of hypercalcitoninemia was $1.6 \%$ in patients with PTC and $1.4 \%$ in patients without PTC at histology, with no significant difference between the 2 groups [16]. Our results, obtained from a large cohort of consecutive patients, are in agreement with the results reported by Rosario and Calsolari [16] and do not support any association between hypercalcitoninemia and cytological results. To confirm our findings, we repeated the analysis in a subgroup of patients submitted to surgery and, similarly, we did not find any difference in the prevalence of hypercalcitoninemia between DTC and benign goiter (8.7 vs. $5.4 \%, p=0.13)$.

On the contrary, several studies evaluated the relationship between hypercalcitoninemia and AIT with conflicting results $[15-17,19]$. Some authors reported the presence of $\mathrm{CCH}$ in some thyroid specimens with Hashimoto's thyroiditis [19], while others reported decreased serum CT values probably caused by atrophy, fibrosis, and destruction of both follicular and C-cells [15]. Recently, Ito et al. [23] found a significant association between ECLIA-CT and TgAb titer: ECLIA-CTs were statistically lower in the TgAb positive group than in the

Hypercalcitoninemia in Non-MTC

Thyroid Nodules
$\mathrm{TgAb}$ negative group suggesting that $\mathrm{CT}$ level might be affected by thyroiditis.

We found a significant increase of hypercalcitoninemia prevalence in patients with NG with respect to NAIT patients. However, when we analyzed our data according to gender, no difference was found between NG and N-AIT patients. We believe that the difference observed in the whole group is probably due to the higher number of females in the group of N-AIT. As a matter of fact, we found significantly lower serum CT levels in females compared to males and consequently lower prevalence of hypercalcitoninemia in females than man. Since the thyroid volume was significantly larger in males than females, we hypothesized a possible association between thyroid volume and CT levels. We found a correlation in patients with thyroid nodular disease between thyroid volume and basal serum CT levels too, in agreement with previous studies $[11,13,24]$. Also in a subgroup of patients submitted to thyroidectomy, the presence of AIT at histology was not associated with a higher prevalence of hypercalcitoninemia. No association between N-AIT and hypercalcitoninemia was also observed when the diagnosis of the autoimmune disease was made based on TPOAb levels. Our results are similar to those reported by Rosario and Calsolari [16] and Grani et al. [15]; however, differently to our study, these authors defined the presence of AIT only based on the positivity of anti-thyroid antibodies without histological or clinical data. Based on followup data, surgery was indicated in $4 / 59(6.8 \%)$ of cases. We found an incidental micro-MTC in only 1 patient and, in another one, a $\mathrm{CCH}$. Our results are similar to those reported by Costante et al. [9] in a subgroup of 171 patients with a slight increase of basal CT values ( $>10$ and $<20 \mathrm{pg} /$ $\mathrm{mL}$ ) in which only 1 patient underwent surgery because of a positive pentagastrin test with histological diagnosis of $\mathrm{CCH}$. In our series of patients with hypercalcitoninemia, we observed a high rate of patients in whom serum CT became undetectable during follow-up. These results were probably due to the inclusion in the study group of patients with a slight increase of serum CT levels. Indeed, we found a significant correlation between basal serum CT level and its trend during the follow-up. Significantly lower levels of basal serum CT were observed in the subgroup of patients in whom serum CT became undetectable (median 11 vs. $24.7 \mathrm{pg} / \mathrm{mL}$ ). In addition, since not all patients with hypercalcitoninemia were submitted to additional serum CT measurement during the follow-up, a possible selection bias might have occurred in our study.

Some limitations of this study are intrinsic to its retrospective design, in particular histological results to rule 
out MTC were not available in all patients. However, the findings from a subgroup of patients submitted to surgery confirm the lack of association between hypercalcitoninemia and both AIT and DTC, as already observed in the cytological series.

On the other hand, the study has several strengths, including a similar diagnostic approach and follow-up strategies in the same institute. In addition, our cohort of patients is the largest, to our knowledge, in which the clinical impact of AIT and DTC on basal serum CT levels has been evaluated in both cytological and histological series.

\section{Conclusion}

Thyroid autoimmune disease and DTC seem not to affect basal serum CT levels in patients with thyroid nodules. Therefore, in the presence of hypercalcitoninemia, MTC should be routinely excluded also in the presence of AIT or a cytological diagnosis of DTC. In addition, our data suggest that an aggressive approach may not be necessary in patients with only a slight increase of basal CT. We believe that an adequate follow-up including serum CT measurement and thyroid ultrasound could be sufficient to identify patients in whom surgical approach may be required, without missing clinically significant MTC.

\section{Statement of Ethics}

All patients gave their written informed consent, and the study protocol was approved by the institute's committee on human research (Comitato Etico Regione Toscana - Area Vasta Sud Est).

\section{Conflict of Interest Statement}

The authors have no conflicts of interest to declare.

\section{Funding Sources}

This study did not receive any funding.

\section{Author Contributions}

F.M. and M.G.C. conceived of the presented idea and wrote the manuscript; C.D., N.B., F.P., and M.C. verified the analytical methods. L.B., T.P., M.C., S.C., C.C., and R.F. contributed to the design and implementation of the research; A.C. performed statistical analysis. All authors discussed the results and contributed to the final manuscript.

\section{References}

1 American Thyroid Association Guidelines Task Force; Kloos RT, Kloos RT, Eng C, Evans DB, Francis GL, Gagel RF, et al. Medullary thyroid cancer: management guidelines of the American Thyroid Association. Thyroid. 2009;19(6):565-612.

2 Elisei R. Routine serum calcitonin measurement in the evaluation of thyroid nodules. Best Pract Res Clin Endocrinol Metab. 2008 Dec;22(6):941-53.

3 Elisei R, Romei C. Calcitonin estimation in patients with nodular goiter and its significance for early detection of MTC: European comments to the guidelines of the American Thyroid Association. Thyroid Res. 2013 Mar 14;6(Suppl 1):S2.

4 Pacini F, Fontanelli M, Fugazzola L, Elisei R, Romei C, Di Coscio G, et al. Routine measurement of serum calcitonin in nodular thyroid diseases allows the preoperative diagnosis of unsuspected sporadic medullary thyroid carcinoma. J Clin Endocrinol Metab. 1994 Apr; 78(4):826-9.

5 Rieu M, Lame MC, Richard A, Lissak B, Sambort B, Vuong-Ngoc P, et al. Prevalence of sporadic medullary thyroid carcinoma: the importance of routine measurement of serum calcitonin in the diagnostic evaluation of thyroid nodules. Clin Endocrinol. 1995 May; 42(5):453-60

6 Elisei R, Bottici V, Luchetti F, Di Coscio G, Romei C, Grasso L, et al. Impact of routine measurement of serum calcitonin on the diagnosis and outcome of medullary thyroid cancer: experience in 10,864 patients with nodular thyroid disorders. J Clin Endocrinol Metab. 2004 Jan;89(1):163-8.

7 Vierhapper H, Niederle B, Bieglmayer C, Kaserer K, Baumgartner-Parzer S. Early diagnosis and curative therapy of medullary thyroid carcinoma by routine measurement of serum calcitonin in patients with thyroid disorders. Thyroid. 2005 Nov; 15(11):1267-72.

8 Papi G, Corsello SM, Cioni K, Pizzini AM, Corrado S, Carapezzi C, et al. Value of routine measurement of serum calcitonin concentrations in patients with nodular thyroid disease: a multicenter study. J Endocrinol Invest. 2006 May;29(5):427-37.

9 Costante G, Meringolo D, Durante C, Bianchi $D$, Nocera M, Tumino S, et al. Predictive value of serum calcitonin levels for preoperative diagnosis of medullary thyroid carcinoma in a cohort of 5817 consecutive patients with thy- roid nodules. J Clin Endocrinol Metab. 2007 Feb;92(2):450-5.

10 Costante G, Durante C, Francis Z, Schlumberger M, Filetti S. Determination of calcitonin levels in C-cell disease: clinical interest and potential pitfalls. Nat Clin Pract Endocrinol Metab. 2009 Jan;5(1):35-44.

11 Karanikas G, Moameni A, Poetzi C, Zettinig G, Kaserer K, Bieglmayer C, et al. Frequency and relevance of elevated calcitonin levels in patients with neoplastic and nonneoplastic thyroid disease and in healthy subjects. J Clin Endocrinol Metab. 2004 Feb;89(2):515-9.

12 Kapoor D, Jones TH. Smoking and hormones in health and endocrine disorders. Eur J Endocrinol. 2005 Apr;152(4):491-9.

13 d'Herbomez M, Caron P, Bauters C, Do Cao C, Schlienger JL, Sapin R, et al. Reference range of serum calcitonin levels in humans: influence of calcitonin assays, sex, age, and cigarette smoking. Eur J Endocrinol. 2007 Dec;157(6):749-55.

14 Castagna MG, Fugazzola L, Maino F, Covelli $\mathrm{D}$, Memmo S, Sestini F, et al. Reference range of serum calcitonin in pediatric population. J Clin Endocrinol Metab. 2015 May;100(5): $1780-4$. 
15 Grani G, Nesca A, Del Sordo M, Calvanese A, Carbotta G, Bianchini M, et al. Interpretation of serum calcitonin in patients with chronic autoimmune thyroiditis. Endocr Relat Cancer. 2012 Jun;19(3):345-9.

16 Rosario PW, Calsolari MR. Influence of chronic autoimmune thyroiditis and papillary thyroid cancer on serum calcitonin levels. Thyroid. 2013 Jun;23(6):671-4.

17 Erdogan MF, Gursoy A, Kulaksizoglu M. Long-term effects of elevated gastrin levels on calcitonin secretion. J Endocrinol Invest. 2006 Oct;29(9):771-5.

18 Toledo SP, Lourenço DM Jr, Santos MA, Tavares MR, Toledo RA, Correia-Deur JE. Hypercalcitoninemia is not pathognomonic of medullary thyroid carcinoma. Clinics. 2009; 64(7):699-706.
19 Guyetant S, Wion-Barbot N, Rousselet MC, Franc B, Bigorgne JC, Saint-Andre JP. C-cell hyperplasia associated with chronic lymphocytic thyroiditis: a retrospective quantitative study of 112 cases. Hum Pathol. 1994 May; 25(5):514-21.

20 Verga U, Ferrero S, Vicentini L, Brambilla T, Cirello V, Muzza M, et al. Histopathological and molecular studies in patients with goiter and hypercalcitoninemia: reactive or neoplastic C-cell hyperplasia? Endocr Relat Cancer. 2007 Jun; 14(2):393-403.

21 Cibas ES, Ali SZ. The 2017 bethesda system for reporting thyroid cytopathology. Thyroid. 2017 Nov;27(11):1341-6.
22 Guan H, de Morais NS, Stuart J, Ahmadi S, Marqusee E, Kim MI, et al. Discordance of serological and sonographic markers for Hashimoto's thyroiditis with gold standard histopathology. Eur J Endocrinol. 2019 Nov; 181(5): 539-44.

23 Ito Y, Kaneko H, Sasaki Y, Ohana N, Ichijo M, Furuya $\mathrm{F}$, et al. Calcitonin levels by ECLIA correlate well with RIA values in higher range but are affected by sex, TgAb, and renal function in lower range. Endocr J. 2020 Apr;14(2): 393-403.

24 Giovanella L, Imperiali M, Ferrari A, Palumbo A, Lippa L, Peretti A, et al. Thyroid volume influences serum calcitonin levels in a thyroid-healthy population: results of a 3-assay, 519 subjects study. Clin Chem Lab Med. 2012 Apr 4;50(5):895-900. 